\title{
Optimized Compensation of Unwanted Current Terms by AC Power Converters Under Generic Voltage Conditions
}

\author{
Danilo Iglesias Brandao, Member, IEEE, Hildo Guillardi Jr., Helmo K. Morales-Paredes, Member, IEEE, \\ Fernando Pinhabel Marafão, Member, IEEE, and José Antenor Pomilio, Senior Member, IEEE
}

\begin{abstract}
This paper formulates an optimization-based algorithm for the compensation of unwanted current terms by means of distributed electronic power converters, such as active power filters and grid-connected inverters. The compensation goal consists in achieving suitable load conformity factors, defined at the source side and within a feasible power region in terms of the power converter capability. Based on the measured load quantities and on a certain objective function, the algorithm tracks the expected source currents, which are thereupon used to calculate proper scaling coefficients and, therefore, the compensation current references. It improves the power quality at the point of common coupling and enables full exploitation of distributed energy resources, increasing their efficiency. The compensation is based on a decoupled current decomposition and on an optimization-based algorithm. In this paper, the strategy is applied to nonlinear and unbalanced three-phase four-wire circuit, under nonsinusoidal and asymmetrical voltage conditions. The steady-state and dynamic behaviors have been analyzed by theoretical, simulation, and experimental results. Furthermore, the proposed approach is also compared to other compensation strategies showing its effectiveness.
\end{abstract}

Index Terms-Distributed power generation, nonsinusoidal voltage, optimized compensation, power filters, power quality.

\section{INTRODUCTION}

$\mathbf{N}$ OWADAYS, the use of electronic power processors (EPPs) for interfacing distributed energy resources (DERs) may be understood as a waste of power electronic capability, if only to inject active power from the primary energy source (PES) into the grid [1], [2]. Particularly in case of

Manuscript received November 12, 2015; revised February 20, 2016 and April 6, 2016; accepted May 23, 2016. Date of publication July 27, 2016; date of current version November 8, 2016. This work was supported in part by the Sao Paulo Research Foundation-FAPESP under Grant 2012/24309-8, Grant 2013/08545-6, and Grant 2014/236911 , and in part by the National Council for Scientific and Technological Development-CNPq under Grant 302257/2015-2 and Grant 487471/2012-1.

D. I. Brandao is with the Department of Electrical Engineering, Federal University of Minas Gerais, Belo Horizonte 31270-010, Brazil (e-mail: dbrandao@cpdee.ufmg.br).

H. Guillardi, Jr., and J. A. Pomilio are with the School of Electrical and Computer Engineering, University of Campinas, Campinas 13083-970, Brazil (e-mail: hildogjr@dsce.fee.unicamp.br; antenor@fee.unicamp.br).

H. K. Morales-Paredes and F. P. Marafão are with the Universidade Estadual Paulista, Sorocaba 18087-180, Brazil (e-mail: hmorales @ sorocaba.unesp.br; fmarafao@ sorocaba.unesp.br).

Color versions of one or more of the figures in this paper are available online at http://ieeexplore.ieee.org.

Digital Object Identifier 10.1109/TIE.2016.2594226 renewable PESs, the intermittent power generation may lead the EPPs to have idle power capacity during significant periods of operation. Thus, multifunctional inverters have been proposed to perform ancillary tasks, such as the compensation of unwanted current terms (reactive, distortion, and unbalance) or voltage regulation, enabling full exploitation of EPPs capability, increasing their cost-benefit and improving the power quality, and efficiency of the power system [3], [4]. In this context, the Pacific Gas and Electric Company [5] has presented the first code in the area with the definition of "smart inverter" as an interfacing power converter that must be able to perform additional tasks, possibly following commands from the distribution provider.

Therefore, it is appealing to manage such EPPs following an optimized procedure that aims to attain, in terms of power quality, the best performance indices defined at the source side and within a previous defined feasible power region.

Most EPP's control schemes can be classified, e.g., based on their reference frame, in synchronous $(d q 0)$, stationary $(\alpha \beta 0)$, and natural $(a b c)$, and such choice is related to the adopted control strategy, the implemented controllers, and the voltage conditions [6], [7]. In [8], an optimal control scheme based on $\alpha \beta 0$-frame and voltages processed through signal conditioning filters to extract the voltage sequence components was proposed. Kanjiya et al. [9], [10] proposed a selective frequency-domain optimal control based on the definition of conductance factors in $a b c$-framework.

Recently, Alfonso-Gil et al. [11] addressed an optimized compensation strategy based on linear matrix inequalities and using the IEEE Standard 1459 to selectively identify the unwanted power terms. It showed superior performance to [12], which introduced a priority-based compensation strategy. However, as the Standard 1459 was not proposed for compensation purposes, that technique is not able to fully decouple load and voltage nonidealities under deteriorated voltage operation, which could lead to nonoptimized compensation (this scenario was not evaluated in [11]). Kanjiya et al. [9] proposed a noniterative optimal control strategy based on the IEEE Standard 519, proving to be effective for dynamic load compensation, requiring one to two cycles $(\approx 30 \mathrm{~ms})$ to achieve the steady state. However, it does not measure the filter currents, which hampers the filter protection during short-circuit. Moreover, it performs sinusoidal current synthesis that may not provide damping capacity against induced resonances [13]. Both recent papers had not dealt with optimized compensation using DERs, on which compensation 


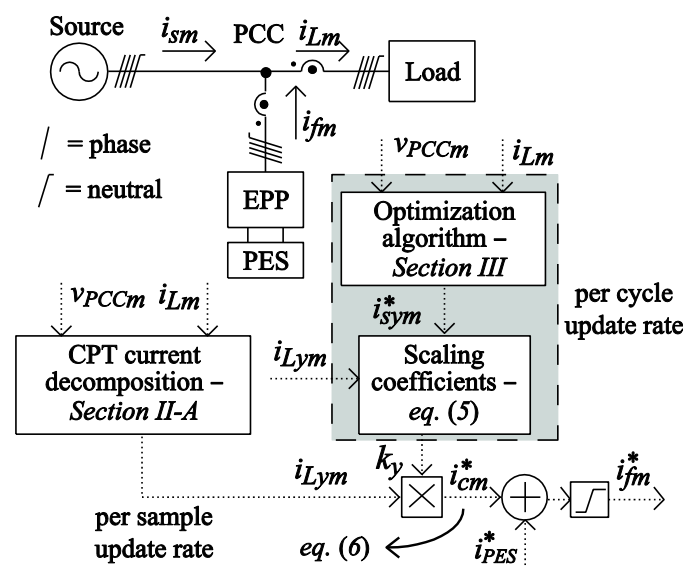

Fig. 1. Three-phase four-wire circuit with the block diagram of the optimized compensation strategy.

capability may vary over time [14], [15]. So, this paper contributes to fill such gap.

Furthermore, many papers based on noniterative optimization-based algorithms (OBAs) have argued that iterative OBAs are difficult to implement and/or present inherent computational delay [9]. However, iterative algorithms have a wide range of linear and nonlinear methods, e.g., Simplex method (SM), interior-point method, quadratic method, primal method, among others, applied to digital implementation [16]. For example, the revised Simplex is a variant of $S M$, in which the main attributes are the economy of memory and computational processing [16].

Therefore, the main goal of this paper is to optimize the compensation of reactive, harmonic, and unbalance current terms, by means of the idle power capacity of distributed EPPs, especially due to intermittent behavior of PES. The proposed compensation uses SM, though any other programming solver could be applied to, and the conservative power theory (CPT) [17]. This latter has been chosen due to its orthogonal current decomposition, which decouples the unwanted load current terms, allowing to selectively compensating them, even under nonsinusoidal voltages. Besides, the CPT's load conformity factors [18] were used to define the power quality constraints, at the source side, such as reactive and unbalance current limits and minimum distortion and power factor requirements, which are rarely investigated [19]-[21].

The optimized compensation is devised as a linear iterative algorithm using standard SM, which has been chosen because of its simplicity of implementation, and good and fast results for problems with limited number of variables and constraints. The proposed method has only one objective function and, thanks to the decoupled CPT's current decomposition, there are no tradeoffs between conflicting objectives, as usual in multiobjective optimization programming [22], [23].

Fig. 1 shows the simplified schematic of a three-phase fourwire circuit, considering the block diagram of the optimized compensation strategy to generate the optimal compensation current references $\left(i_{\mathrm{cm}}^{*}\right)$. The load quantities are measured and used to process the CPT's current terms $\left(i_{\mathrm{Lym}}\right)$ and the optimization algorithm. The converter output currents $\left(i_{\mathrm{fm}}\right)$ are also measured and used into the current control loop, as usually employed in EPPs [6], though not shown in Fig. 1.

The optimization block returns the expected source currents $\left(i_{\mathrm{Sym}}^{*}\right)$, which are thereupon used to calculate the scaling coefficients $\left(k_{y}\right)$ and, therefore, the compensation current references to be applied to EPP's current control loop.

This paper is an extended version of [24], emphasizing a description of the state of the art, analyzing operation under distorted and asymmetrical voltages, presenting further simulation and experimental results and comparing the proposed approach with other proposals in the literature.

\section{REQUIRED BACKGROUND OF CPT}

CPT [17] is a time-domain power-based theory, valid for single- and three-phase systems, with three- or four-wire circuits, independent of the purity of voltage and current waveforms, as required by other power theories [25].

\section{A. Current Decomposition}

CPT splits the instantaneous currents into different orthogonal current terms, which are directly related to load behavior. Let us assume a multiphase circuit where each particular phase of the system is denoted by the subscript " $m$ ":

1) balanced active current $\left(i_{\mathrm{am}}^{b}\right)$ is the term related to the active power consumption (useful work);

2) balanced reactive current $\left(i_{\mathrm{rm}}^{b}\right)$ is the term related to the reactive power circulation (i.e., reactive energy);

3) void current $\left(i_{\mathrm{vm}}\right)$ is the term related to the nonlinear (distortion) behavior between voltages and load currents;

4) unbalanced current $\left(i_{m}^{u}\right)$ is the term related to the unbalanced load among the system's phases;

5) nonactive current $\left(i_{\text {nam }}\right)$ is the term that represents all the unwanted terms of the current.

By definition, the collective rms current (in bold) can be split into

$$
\boldsymbol{I}^{2}=\boldsymbol{I}_{a}^{b^{2}}+\boldsymbol{I}_{n a}^{2}=\boldsymbol{I}_{a}^{b^{2}}+\boldsymbol{I}_{r}^{b^{2}}+\boldsymbol{I}_{v}^{2}+\boldsymbol{I}^{u 2} .
$$

Note that each current term is orthogonal to each other. Thus, multiplying the collective rms current and voltage, the apparent power $A$ can be decomposed into

$$
A^{2}=\boldsymbol{V}^{2} \cdot \boldsymbol{I}^{2}=P^{2}+Q^{2}+D^{2}+N^{2}
$$

where $P$ is the active power, $Q$ is the reactive power, $D$ is the distortion power, and $N$ is the unbalance power. Complementary analyses of the current and power components can be found in [17].

\section{B. Load Conformity Factors}

Considering the previous definition, the main idea behind the CPT is to identify power and current terms directly proportional to load characteristics, such as unbalance, nonlinearities, and reactivity, independent of supply voltage conditions. So, the CPT's conformity factors follow the same concept, focusing on the identification and quantification of the load phenomena. Thus, in order to characterize different aspects of load behavior, the load conformity factors were proposed in [18] as follows: 
1) power factor $(\lambda)$ is a general polyphase efficiency ratio, which is affected by reactive power, unbalanced loads, and nonlinearities. Unity power factor represents current waveforms proportional to voltage waveforms (as in case of balanced resistive loads);

2) reactivity factor $\left(\lambda_{Q}\right)$ reveals the presence of reactive energy in linear inductors or capacitors, or even phase shifts due to nonlinear loads (e.g., thyristor rectifiers);

3) distortion factor $\left(\lambda_{D}\right)$ indicates the presence of voltage and current's nonlinearities;

4) unbalance factor $\left(\lambda_{N}\right)$ indicates the effect of load unbalance.

Except for the power factor, all the other conformity factors are zero for ideal conditions, regardless of the voltage distortion or symmetry

$$
\begin{aligned}
\lambda & =\frac{\boldsymbol{I}_{a}^{b}}{\sqrt{\boldsymbol{I}_{a}^{b^{2}}+\boldsymbol{I}_{n a}^{2}}}=\frac{\boldsymbol{I}_{a}^{b}}{\boldsymbol{I}}=\frac{P}{A} \\
\lambda_{Q} & =\frac{\boldsymbol{I}_{r}^{b}}{\sqrt{\boldsymbol{I}_{a}^{b^{2}}+\boldsymbol{I}_{r}^{b^{2}}}}=\frac{Q}{\sqrt{P^{2}+Q^{2}}} \\
\lambda_{D} & =\frac{\boldsymbol{I}_{v}}{\sqrt{\boldsymbol{I}_{a}^{b^{2}}+\boldsymbol{I}_{r}^{b^{2}}+\boldsymbol{I}_{v}^{2}+\boldsymbol{I}^{u 2}}}=\frac{\boldsymbol{I}_{v}}{\boldsymbol{I}}=\frac{D}{A} \\
\lambda_{N} & =\frac{\boldsymbol{I}^{u}}{\sqrt{\boldsymbol{I}_{a}^{b^{2}}+\boldsymbol{I}_{r}^{b^{2}}+\boldsymbol{I}^{u 2}}}=\frac{N}{\sqrt{P^{2}+Q^{2}+N^{2}}} .
\end{aligned}
$$

From (3), the load conformity factors are related to the power factor as in

$$
\lambda=\sqrt{\left(1-\lambda_{Q}^{2}\right) \cdot\left(1-\lambda_{D}^{2}\right) \cdot\left(1-\lambda_{N}^{2}\right)} .
$$

\section{Relation of CPT'S Load Conformity Factors to Conventional Power Quality Indices}

Under ideal voltage conditions, for single- and three-phase circuits, the CPT's factors lead to the same conclusions and values of the conventional power quality indices, such as total harmonic distortion (THD), unbalance factors, and displacement factor. Thus, considering sinusoidal and symmetrical voltages, $\lambda$ results equal to the traditional fundamental displacement factor $\left(\cos \phi_{1}\right)$, where $\phi_{1}$ is the phase angle between fundamental phase voltage and current. For single- or balanced three-phase circuits, $\lambda_{Q}$ could be calculated as $\lambda_{Q}=\sin (\phi 1)$. $\lambda_{D}$ can be associated with the conventional current $\mathrm{THD}_{\mathrm{i}}$ by $\lambda_{D}=\mathrm{THD}_{i} / \sqrt{1+\mathrm{THD}_{i}^{2}}$, and finally, $\lambda_{N}$ can be related to the traditional positive, negative, and zero sequence unbalance factors [26].

However, if the voltages are not sinusoidal, the CPT's factors show how a generic load circuit may affect the current and power terms at the PCC. In such a case, $\lambda_{D}$ may be slightly affected by the scattering phenomena (such as skin effect) imposed by distorted voltages [17], but such an influence is rather limited as the voltage distortions (THD) were lower than $10 \%$. Besides, the information from such conformity factors is related to the entire polyphase circuit, and not only to single-phase variables.
Thus, the trick in handling the CPT to define the compensation current references and the load conformity factors to set the constraints, instead of conventional power quality, is that the CPT's factors are concentrated on the load characteristics and not just on the current waveforms, which can be highly influenced by voltage conditions.

\section{Flexible and Selective Generator of Compensation Currents}

The generator of compensation currents adjusts some coefficients to scale the magnitude of the decomposed CPT's current terms, within any percentage. Thanks to their orthogonal characteristic, it is possible to minimize individually and accurately any of the unwanted current terms.

Based on Kirchhoff's current law, each scaling coefficient is a ratio of its collective load current term. By definition, they must range from 0 to 1

$$
k_{y}=\frac{\boldsymbol{I}_{L y}-\boldsymbol{I}_{s y}^{*}}{\boldsymbol{I}_{L y}}, 0 \leq k_{y} \leq 1
$$

such that the superscript " $*$ " means desired (reference) value, and the subscript " $y$ " can assume $Q, D$, or $N$ to represent the balanced reactive, distortion, or unbalance scaling coefficients.

To generate the EPP compensation current reference $i_{c m}^{*}$ for each phase, according to the notation criteria defined in Fig. 1, it has been defined as

$$
i_{c m}^{*}=k_{Q} \cdot i_{L r m}^{b}+k_{D} \cdot i_{L v m}+k_{N} \cdot i_{L m}^{u}=k_{n a} \cdot i_{L n a m} .
$$

Note that unity scaling coefficients correspond to full compensation because the references turn equal to the nonactive load currents $i_{\text {Lnam }}$, allowing EPP to cancel them. The zero scaling coefficients mean no compensation $\left(i_{c m}^{*}=0\right)$.

From (5) and (6), one can note that to generate the compensation current references, it is enough to find the source currents $\left(\boldsymbol{I}_{\text {sy }}^{*}\right)$, which are the aim of the optimization algorithm of Fig. 1, and it is shown in Section III.

\section{Optimized Compensation Based on Linear Programming Problem}

The standard model of SM is

$$
\begin{array}{ll}
(\min ) & z=\underline{c} \cdot \underline{x} \\
\text { s.t. } & \underline{A} \cdot \underline{x} \leqslant \underline{b} \\
& \underline{x} \geqslant \underline{0}
\end{array}
$$

where $z$ is the objective function and the underlined variables are matrices; $\underline{c}$ is the matrix of the objective function coefficients; $\underline{A}$ is the matrix of the constraint coefficients; and $\underline{b}$ is the matrix of the limits. The last constraint requires that all the variables $(\underline{x})$ are nonnegative.

\section{A. Linearization}

To preserve the orthogonality among the decomposed CPT's current terms, the variables of the linear problem are defined as 
the collective squared values of each source current term, which are all nonnegative variables, as follows:

1) $X_{P}$ : collective squared value of the source balanced active currents $\left(\boldsymbol{I}_{\mathrm{sa}}^{b^{2}}\right)$;

2) $X_{Q}$ : collective squared value of the source balanced reactive currents $\left(\boldsymbol{I}_{\mathrm{sr}}^{b^{2}}\right)$

3) $X_{D}$ : collective squared value of the source void currents $\left(I_{\mathrm{SV}}^{2}\right)$

4) $X_{N}$ : collective squared value of the source unbalanced currents $\left(\boldsymbol{I}_{s}^{u^{2}}\right)$.

Then, rewriting (3) based on the previous linear variables, the squared values of each load conformity factor are

$$
\begin{aligned}
\lambda^{2} & =\frac{X_{P}}{X_{P}+X_{Q}+X_{D}+X_{N}} \\
\lambda_{Q}^{2} & =\frac{X_{Q}}{X_{P}+X_{Q}} \\
\lambda_{D}^{2} & =\frac{X_{D}}{X_{P}+X_{Q}+X_{D}+X_{N}} \\
\lambda_{N}^{2} & =\frac{X_{N}}{X_{P}+X_{Q}+X_{N}} .
\end{aligned}
$$

\section{B. Objective Function}

The objective function is set to minimize the unwanted currents at the source side, while the weighting coefficients are used to assign relative importance to some terms over the others. These coefficients are represented in (9) by the squared values of each unwanted load current term $\underline{c}=\left[\boldsymbol{I}_{L r}^{b}, \boldsymbol{I}_{L v}, \boldsymbol{I}_{L}^{u}\right]$. Thus, the highest collective rms value, representing the most significant unwanted current term presented at the load side, is prioritized. It differs from other proposals as [11], [12]

$$
(\min ) z=X_{Q} \cdot \boldsymbol{I}_{L r}{ }^{b^{2}}+X_{D} \cdot \boldsymbol{I}_{L v}{ }^{2}+X_{N} \cdot \boldsymbol{I}_{L}^{u}{ }^{2} .
$$

\section{Constraints and Limits}

Taking advantage of the formulated problem based on sourceside quantities, it is possible to define a set of conformity factor constraints. It goes beyond of other approaches (e.g., [11]) that have defined only current limitation constraints, which are also taken into account here.

The conformity factor constraints are defined handling [8] and setting the factors as preset references, respectively,

$$
\begin{aligned}
& X_{Q}+X_{D}+X_{N} \leq X_{P} \cdot\left(\frac{1-\lambda^{* 2}}{\lambda^{* 2}}\right) \\
& X_{Q} \leq X_{P} \cdot\left(\frac{\lambda_{Q}^{* 2}}{1-\lambda_{Q}^{* 2}}\right) \\
& -X_{Q}+X_{D} \cdot \frac{\left(1-\lambda_{D}^{* 2}\right)}{\lambda_{D}^{* 2}}-X_{N} \leq X_{P} \\
& -X_{Q}+X_{N} \cdot \frac{\left(1-\lambda_{N}^{* 2}\right)}{\lambda_{N}^{* 2}} \leq X_{P} .
\end{aligned}
$$

The reference values of the conformity factors may be set according to up-to-date standards relating the CPT's conformity factors as in Section II-C. Those references may be preset by manufacturers based on the local standards or, online set by the distribution provider as per a smart inverter.

$X_{P}$ can always be calculated according to Fig. 1

$$
X_{P}=\boldsymbol{I}_{L a}{ }^{b^{2}}-\boldsymbol{I}_{P E S}^{*}{ }^{2}
$$

where $\boldsymbol{I}_{\mathrm{PES}}^{*}$ is the actual active current reference of PES. Naturally, for active power filter (APF) applications are about zero, whereas for DERs, $\boldsymbol{I}_{\mathrm{PES}}^{*}$ can be provided, for example, by maximum power point tracking techniques.

In addition, a last thermal constraint is needed due to the converter construction. The value of the collective rms current through EPP must not be higher than its nominal collective rate $\left(\boldsymbol{I}_{f} \leq \boldsymbol{I}_{\text {nom }}\right)$. Thus, considering the polarities of Fig. 1, we have

$$
\left(\boldsymbol{I}_{L}-\boldsymbol{I}_{s}\right) \leq \boldsymbol{I}_{n o m}
$$

The active power injection takes priority over compensation. Then, the EPP available capability $\left(\Delta \boldsymbol{I}_{\mathrm{f}}\right)$ for current compensation is

$$
\Delta \boldsymbol{I}_{f}=\sqrt{\boldsymbol{I}_{n o m}^{2}-\boldsymbol{I}_{P E S}^{*}{ }^{2}} .
$$

Of course, for APF applications, $\Delta \boldsymbol{I}_{f}$ is always approximately equal to its own nominal current.

Then, considering only the unwanted current terms and assuming top priority to the active current injection, (12) can be rewritten using (13) as

$$
\left(\boldsymbol{I}_{L n a}-\boldsymbol{I}_{s n a}\right) \leq \Delta \boldsymbol{I}_{f} \leftrightarrow \boldsymbol{I}_{s n a} \geq\left(\boldsymbol{I}_{L n a}-\Delta \boldsymbol{I}_{f}\right) .
$$

Thus, after further rewriting (14), in terms of their squared values, the current limitation constraint is found

$$
X_{Q}+X_{D}+X_{N} \geq\left(\boldsymbol{I}_{L n a}-\Delta \boldsymbol{I}_{f}\right)^{2}
$$

such that if $\Delta \boldsymbol{I}_{f} \geq \boldsymbol{I}_{L n a}$ means full compensation.

It is worth mentioning that (15) prevents the algorithm to converge, in steady state, to a point that would request higher current than the converter's nominal capacity.

\section{Standard Linear Programming Model}

Finally, the linear programming problem in its standard model as in (7) can be described by the following matrices:

$$
\begin{aligned}
& \underline{c}_{1}=\left[\boldsymbol{I}_{\mathrm{Lr}}{ }^{b^{2}} \boldsymbol{I}_{\mathrm{Lv}}{ }^{2} \boldsymbol{I}_{L}^{u}{ }^{2}\right], \quad \underline{A}=\left[\begin{array}{ccc}
1 & 1 & 1 \\
1 & 0 & 0 \\
-1 & \frac{\left(1-\lambda_{D}^{* 2}\right)}{\lambda_{D}^{* 2}} & -1 \\
-1 & 0 & \frac{\left(1-\lambda_{N}^{* 2}\right)}{\lambda_{N}^{* 2}} \\
-1 & -1 & -1
\end{array}\right] \\
& \underline{x}=\left[\begin{array}{c}
X_{Q} \\
X_{D} \\
X_{N}
\end{array}\right], \quad \underline{b}=X_{P} \cdot\left[\begin{array}{c}
\left(\frac{1-\lambda^{* 2}}{\lambda^{* 2}}\right) \\
\left(\frac{\lambda_{Q}^{* 2}}{1-\lambda_{Q}^{* 2}}\right) \\
1 \\
1 \\
\frac{-\left(\boldsymbol{I}_{\mathrm{Lna}}-\Delta \boldsymbol{I}_{f}\right)^{2}}{X_{P}}
\end{array}\right]
\end{aligned}
$$




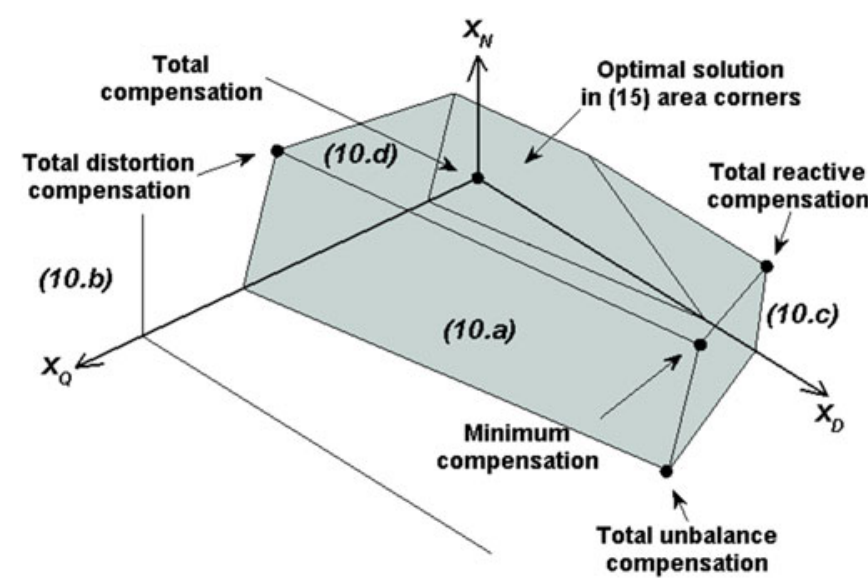

Fig. 2. Geometrical interpretation of optimized compensation linear problem.

where all the variables are nonnegative. Note that (15) has been multiplied by " -1 " to fit in the standard SM. For single-phase applications, the quantities related to the unbalance term must be disregarded.

The solution found through SM represents the expected optimal source current terms $\left(\boldsymbol{I}_{\mathrm{sy}}^{*}\right)$, mentioned in Section II-D. Therefore, the scaling coefficients are calculated by (5) and applied to (6) to generate the compensation current references for each phase $m\left(i_{\mathrm{cm}}^{*}\right)$.

\section{E. Geometrical Interpretation}

SM allows a geometrical interpretation of the linear problem, where the axes of Fig. 2 are the linear variables defined in Section III-A, and the constraint inequalities (10) and (15) shape the planes. The feasible solutions made up the bound volume (darker areas) and the optimal feasible solution is always located in one of its corners, driven by the objective function. In summary, SM moves along the boundary of the feasible area until reaching the optimal point. Note that the plane formed by (15) is variable with respect to the PES actual power and dependable on the available capability of $\operatorname{EPP}\left(\Delta \boldsymbol{I}_{f}\right)$.

By construction, the full compensation is located at the origin $\left(\mathrm{X}_{\mathrm{Q}}, \mathrm{X}_{\mathrm{D}}, \mathrm{X}_{\mathrm{N}}\right)=(0,0,0)$, meaning that the unwanted currents have vanished at the source side. One can see that every corner in Fig. 2 has a particular meaning that represents different compensation strategies (e.g., total unbalance compensation). The optimal solution is always located in one of the area corners formed by (15) because it has the minimum value of the objective function and it complies with all the constraints.

It is also possible to define the minimum compensation point, which corresponds to the minimum collective rms current $\left(\boldsymbol{I}_{c}^{\mathrm{min}}\right)$ required to comply with the preset constraints. The minimum compensation point can be found by changing the weighting coefficients of matrix $c$ to (17), which represents the minimum value of this objective function

$$
\underline{c}_{2}=\left[\begin{array}{lll}
\frac{-1}{\boldsymbol{I}_{L r} b^{2}} & \frac{-1}{\boldsymbol{I}_{L v}{ }^{2}} & \frac{-1}{\boldsymbol{I}_{L}^{u}}
\end{array}\right] .
$$

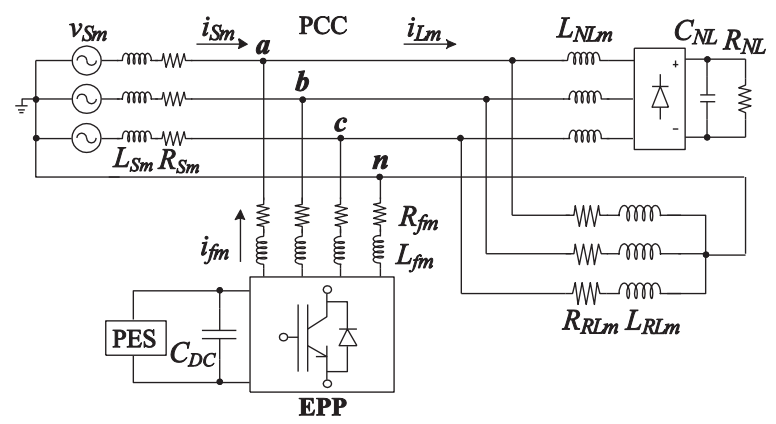

Fig. 3. Nonlinear and unbalance three-phase four-wire circuit.

TABLE I

Parameters of Source Voltage, LoAd, AND EPP

\begin{tabular}{|c|}
\hline Load parameters \\
\hline $\begin{array}{l}R_{\mathrm{RLa}}=4.4 \Omega ; \quad L_{\mathrm{RLa}}=15 \mathrm{mH} ; R_{\mathrm{RLb}}=4.1 \Omega ; \\
L_{\mathrm{RLb}}=18 \mathrm{mH} ; R_{\mathrm{RLc}}=3.7 \Omega ; L_{\mathrm{RLc}}=30 \mathrm{mH}\end{array}$ \\
\hline $\begin{array}{l}L_{\mathrm{NLa}}=1 \mathrm{mH} ; \quad L_{\mathrm{NLb}}=1 \mathrm{mH}, \quad L_{\mathrm{NLc}}=1 \mathrm{mH} \\
R_{\mathrm{NL}}=42 \Omega ; C_{\mathrm{NL}}=2.35 \mathrm{mF} .\end{array}$ \\
\hline EPP parameters \\
\hline$L_{f m}=1.5 \mathrm{mH} ; \quad R_{\mathrm{fm}}=0.1 \Omega ; \quad C_{\mathrm{DC}}=4.7 \mathrm{mF} ;$ \\
\hline Sinusoidal three-phase source $(60 \mathrm{~Hz})$ \\
\hline $\begin{array}{l}V_{\mathrm{sa}}=127 \angle 0^{\circ} \mathrm{V} ; \quad V_{\mathrm{sb}}=127 \angle-120^{\circ} \mathrm{V} ; \\
V_{\mathrm{sc}}=127 \angle 120^{\circ} \mathrm{V} ; L_{\mathrm{Sm}}=0.5 \mathrm{mH} ; \quad R_{\mathrm{Sm}}=0.05 \Omega .\end{array}$ \\
\hline
\end{tabular}

TABLE II

LoAd CURRENT TeRMS AND LOAD CONFORMITY FACTORS

\begin{tabular}{lclll}
\hline \hline \multicolumn{6}{c}{ Collective RMS load current values [A] } \\
\hline $\boldsymbol{I}_{L}=32.6$ & $\boldsymbol{I}_{L a}^{b}=21.7$ & $\boldsymbol{I}_{L r}^{b}=23.3$ & $\boldsymbol{I}_{L v}=4.3$ & $\boldsymbol{I}_{L}^{u}=5.8$ \\
\hline \multicolumn{6}{c}{ Load conformity factors } \\
\hline$\lambda_{L}=0.666$ & $\lambda_{L Q}=0.732$ & $\lambda_{L D}=0.132$ & $\lambda_{L N}=0.179$ \\
\hline \hline
\end{tabular}

If $\Delta \boldsymbol{I}_{f}$ becomes too limited up to not allowing the current compensation to comply with the requirements, which means $\Delta \boldsymbol{I}_{f}<\boldsymbol{I}_{c}^{\mathrm{min}}$, then the Simplex algorithm must be, temporally, disregarded and the EPP should compensate as much as possible, calculating the nonactive scaling coefficient as

$$
k_{n a}=\frac{\Delta \boldsymbol{I}_{f}}{\boldsymbol{I}_{L n a}}
$$

and applying it to (6). This strategy corresponds to setting all the weighting coefficients equally, not assigning priority to compensation.

\section{Theoretical Analysis and Simulation Results}

To analyze the proposed strategy, the three-phase four-wire circuit of Fig. 3 has been considered. A three-phase four-leg inverter with wide bandwidth current control loop was connected to the system representing a three-phase distributed EPP. The source voltages $\left(v_{\mathrm{Sm}}\right)$ and the three-phase load are shown in Table I. The respective CPT's load current terms and conformity factors are shown in Table II. 
TABLE III

THEORETICAL RESULTS FOR MINIMUM COMPENSATION (MATLAB)

\begin{tabular}{cccc}
\hline \hline$\lambda^{*}=0.920$ & $\lambda_{Q}^{*}=0.400$ & $\lambda_{D}^{*}=0.080$ & $\lambda_{N}^{*}=0.070$ \\
$\boldsymbol{I}_{\mathrm{sa}}^{b}=21.70 \mathrm{~A}$ & $\boldsymbol{I}_{\mathrm{sr}}^{b-* \text { in }}=8.90 \mathrm{~A}$ & $\boldsymbol{I}_{\mathrm{sv}}^{* m}=1.89 \mathrm{~A}$ & $\boldsymbol{I}_{s}^{u-* m i n}=1.65 \mathrm{~A}$ \\
- & $k_{Q}=0.618$ & $k_{D}=0.561$ & $k_{N}=0.716$ \\
- & $\boldsymbol{I}_{\mathrm{fr}}^{b}=14.40 \mathrm{~A}$ & $\boldsymbol{I}_{\mathrm{fv}}=2.41 \mathrm{~A}$ & $\boldsymbol{I}_{f}^{u}=4.15 \mathrm{~A}$ \\
$\boldsymbol{I}_{\mathrm{sa}}^{b}=21.70 \mathrm{~A}$ & $\boldsymbol{I}_{\mathrm{sr}}^{b}=8.90 \mathrm{~A}$ & $\boldsymbol{I}_{\mathrm{sv}}^{b}=1.89 \mathrm{~A}$ & $\boldsymbol{I}_{s}^{u}=1.65 \mathrm{~A}$ \\
$\lambda^{\mathrm{pcc}}=0.920$ & $\lambda_{Q}^{\mathrm{pcc}}=0.379$ & $\lambda_{D}^{\mathrm{pcc}}=0.080$ & $\lambda_{N}^{\mathrm{pcc}}=0.070$ \\
\hline \hline
\end{tabular}

\section{A. Theoretical Results}

The system of Fig. 3 was implemented in MATLAB code in order to evaluate the impact of the optimization algorithm on the EPP operation and its cost effectiveness, which is meant to express the capability to process more amount of power/current in an efficient way, without modifying the nominal capacity and cost of an electronic power converter. Let us consider a stiff grid where the PCC voltages are constant along the compensation process. Then, as an example, let us assume possible references for the conformity factors, such those indicated in Table III. These values were empirically defined based on the author's experience.

The minimum compensation objective function (17) applied to the SM (7) returns the minimum source current terms (second row in Table III), which are used to calculate the scaling coefficients (5). Finally, through (6), the compensation current references $\left(i_{f m}^{*}\right)$ are generated. For this theoretical study, $i_{\mathrm{fm}}^{*}=i_{\mathrm{cm}}^{* \mathrm{~min}}$, since for APF $\boldsymbol{I}_{\mathrm{PES}}^{*} \approx 0$. The EPP's current controller tracks $i_{\mathrm{fm}}^{*}$ minimizing the unwanted current terms at the source side (fifth row in Table III). Finally, the PCC conformity factors are calculated, and they match the requested factors.

As shown in Fig. 2, the minimum compensation point $\left(\mathrm{X}_{\mathrm{Q}}, \mathrm{X}_{\mathrm{D}}, \mathrm{X}_{\mathrm{N}}\right)=\left(8.90^{2}, 1.89^{2}, 1.65^{2}\right)$ requires $15.18 \mathrm{~A}$ of EPP's collective current (fourth row in Table III). Considering any other point, for example, $\left(\mathrm{X}_{\mathrm{Q}}, \mathrm{X}_{\mathrm{D}}, \mathrm{X}_{\mathrm{N}}\right)$ $=\left(9.24^{2}, 0.0^{2}, 0.0^{2}\right)$, on which the PCC factors are $\left(\lambda^{\mathrm{pcc}}=\right.$ $0.916, \lambda_{Q}^{\mathrm{pcc}}=0.4, \lambda_{D}^{\mathrm{pcc}}=0$, and $\left.\lambda_{N}^{\mathrm{pcc}}=0\right)$ and also complies with the initial requirements (but with worse power factor), it needs $15.82 \mathrm{~A}$. The difference of $0.64 \mathrm{~A}$ is negligible considering linear scale $(\approx 4 \%)$. However, it is significant in orthogonal scale $\left(\sqrt{15.82^{2}-15.18^{2}}=4.45 \mathrm{~A}\right)$, which represents about $30 \%$. Then, applying the optimization to EPPs allows them to save extra $30 \%$ amperes for any additional task, such as compensation of unwanted currents.

1) Discussion of Prioritized Selective Compensation: Prioritization strategies for selective compensation schemes have been discussed in some papers such as [27]. Alfonso-Gil et al. [11] recommended equally ranking the disturbing current references. On the other hand, Singh and Verma [12] proposed to give preference first to harmonics, then to unbalance, and finally to reactive compensation. Herein, we have proposed to prioritize the highest collective rms value of load current, as in (9). Thus, assuming the feasible area of Table III (top row), the three proposals have been theoretically analyzed through the circuit of Fig. 3. In order to get similar behavior in terms of the relative importance given to the unwanted current terms, the proposal from [11] was performed by (18), which
TABLE IV

COMPARISON OF PRIORITIZATION OF SELECTIVE COMPENSATION

\begin{tabular}{lccc}
\hline \hline Proposal & Scaling coeffs. & Conf. factors & Currents [A] \\
\hline$[11]$ & $k_{Q}=\mathrm{k}_{\mathrm{D}}=\mathrm{k}_{\mathrm{N}}=0.728$. & $\lambda=0.956 ; \lambda_{Q}=0.280 ;$ & $\boldsymbol{I}_{s}=22.55 ;$ \\
& & $\lambda_{D}=0.051 ; \lambda_{N}=0.070 . \boldsymbol{I}_{f}=\mathbf{1 7 . 6 8}$. \\
{$[11]$} & $k_{Q}=\mathrm{k}_{\mathrm{D}}=\mathrm{k}_{\mathrm{N}}=0.622$. & $\lambda=0.920 ; \lambda_{Q}=0.376 ;$ & $\boldsymbol{I}_{s}=23.22 ;$ \\
& & $\lambda_{D}=0.069 ; \lambda_{N}=\mathbf{0 . 0 9 3 .} \boldsymbol{I}_{f}=\mathbf{1 5 . 1 0}$. \\
{$[12]$} & $k_{Q}=0.603 ; k_{D}=1 ;$ & $\lambda=0.920 ; \lambda_{Q}=0.393 ;$ & $\boldsymbol{I}_{s}=23.51 ;$ \\
& $k_{N}=1$. & $\lambda_{D}=0.000 ; \lambda_{N}=0.000 . \boldsymbol{I}_{f}=15.67$. \\
Here & $k_{Q}=0.618 ; k_{D}=0.561 ;$ & $\lambda=0.920 ; \lambda_{Q}=0.379 ;$ & $\boldsymbol{I}_{s}=23.31 ;$ \\
& $k_{N}=0.716$. & $\lambda_{D}=0.080 ; \lambda_{N}=0.070 . \boldsymbol{I}_{f}=\mathbf{1 5 . 0 8}$. \\
\hline \hline
\end{tabular}

corresponds to setting all the weighting coefficients equally; while the proposal from [12] was performed by (9), replacing the weighting coefficients $\left(\boldsymbol{I}_{L r} b^{2}, \boldsymbol{I}_{L v}{ }^{2}, \boldsymbol{I}_{L}^{u 2}\right)$ to $(10,500,100)$, as in [11]. The comparison results are depicted in Table IV.

From Table IV, one can notice that the solution proposed in [11] needs $17.68 \mathrm{~A}$ to attain the requested conformity factors, or 15.10 A to comply with the power factor. However, $\lambda_{N}=0.093$ remains out of the feasible solution. The proposal in [12] needs 15.67 A to achieve the feasible solution. Conversely, the strategy proposed here requests $15.08 \mathrm{~A}$ to match all the preset conformity factors.

\section{B. Simulation Results}

To analyze the proposed methodology and the system dynamic behavior under distorted and asymmetrical voltages, the circuit shown in Fig. 3 was simulated using PSIM software and the linear programming using MATLAB (see appendix). The PCC voltages have been set to have $3 \%$ of third, fifth, and seventh harmonics, totalizing THD of $5.2 \%$, and $-3 \%$ (phase $a$ ) and $3 \%$ (phase $c$ ) of asymmetry. The same conformity factor references from Table III were considered.

1) PES Power Variation Under Nonideal Voltages Operation: Considering the EPP nominal collective current equal to $40 \mathrm{~A}$, the PES power generation has been varied for three different cases. \#1) $\Delta \boldsymbol{I}_{f} \geq \boldsymbol{I}_{\text {Lna }}$; \#2) $\boldsymbol{I}_{\text {Lna }}>\Delta \boldsymbol{I}_{f} \geq$ $\left.\boldsymbol{I}_{c}^{\mathrm{min}}\right)$; \#3) $\Delta \boldsymbol{I}_{f}<\boldsymbol{I}_{c}^{\mathrm{min}}$. The results are shown in Figs. 4 and 5 .

At the beginning of the simulation (interval \#1), EPP has enough available power capacity to compensate all the unwanted load currents. Thus, all the scaling coefficients are unitary, as well as $\lambda$. The performed compensation strategy is resistive load synthesis and not sinusoidal current synthesis, as discussed in Section I. Then, the source current waveforms are proportional to the PCC voltages and have about $5.2 \%$ of $\mathrm{THD}_{\mathrm{is}}$ and low neutral current (see bottom of Fig. 5). The residual neutral current is related to the PCC voltage nonidealities (unbalances and third-order harmonics). As discussed in Section II-C, the CPT's factors are concentrated on the load behavior and not just on the current waveforms.

After $0.15 \mathrm{~s}$ (interval \#2), PES increases its power generation forcing EPP to reduce its compensation rate (see $\Delta \boldsymbol{I}_{f}$ on top of Fig. 4) because the active power injection is considered as the top priority in the optimization algorithm by means of (13). However, the optimized compensation operates at the optimal 


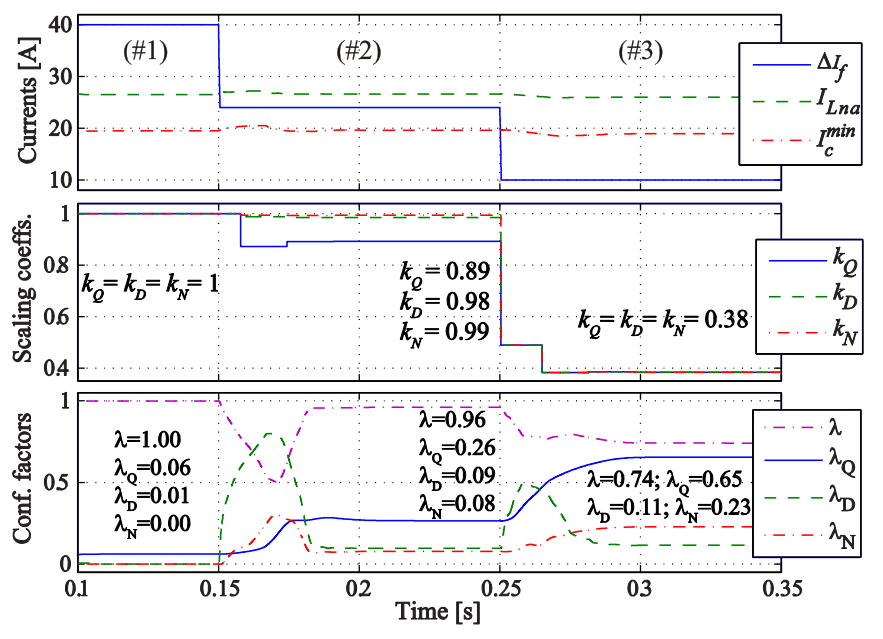

Fig. 4. Optimized compensation under PES power variation and nonideal voltages operation. From top to bottom: currents, scaling coefficients, and PCC conformity factors.

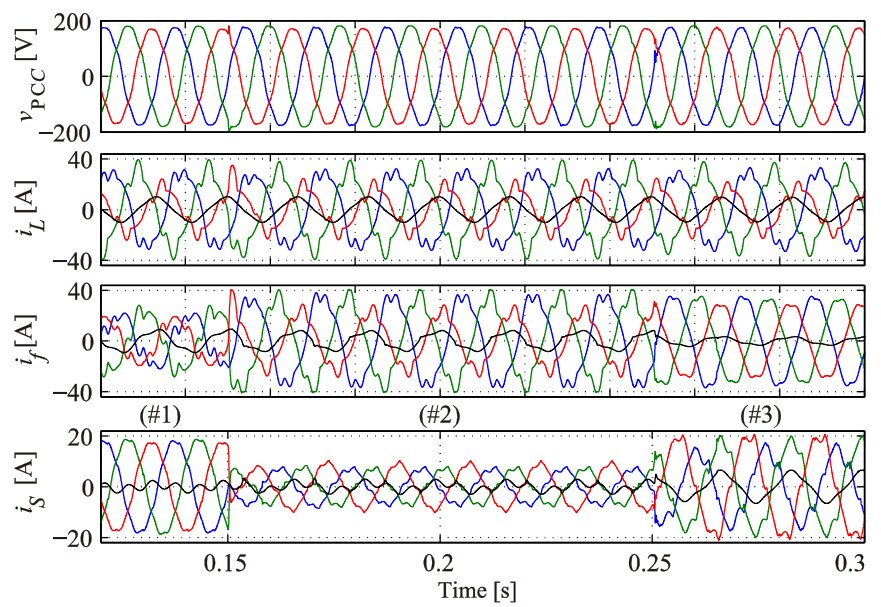

Fig. 5. Optimized compensation under PES power variation and nonideal voltages operation. From top to bottom: PCC voltages, load, filter, and source current waveforms.

TABLE V

LoAd AND SOURCE CURRENT HARMONICS DURING PES POWER VARIATION UNDER NONIDEAL VOLTAGES OPERATION

\begin{tabular}{lcccc}
\hline \hline Current & THD $_{\text {iL }}$ & THD $_{\text {is }}$ 1 & THD $_{\text {is }}$ 2 & THD $_{\text {is }}$ 3 \\
\hline phase $a$ & $17.40 \%$ & $5.67 \%$ & $13.15 \%$ & $16.39 \%$ \\
phase $b$ & $17.02 \%$ & $4.75 \%$ & $16.77 \%$ & $15.61 \%$ \\
phase $c$ & $22.92 \%$ & $4.90 \%$ & $10.35 \%$ & $11.81 \%$ \\
\hline \hline
\end{tabular}

point in steady state. It maximizes the compensation of the unwanted current terms, and practically complies with the required conformity factors.

After $0.25 \mathrm{~s}$ (interval \#3), the power generation increases close to the PES nominal value. Then, EPP cannot comply anymore with the preset constraints and it must run using (18) to compensate as much unwanted currents as possible. See Table V to compare the $\mathrm{THD}_{\mathrm{is}}$ of current source between the three simulated intervals.

With respect to the dynamic response aspect, the main objective of an OBA applied to compensation purpose is the operation

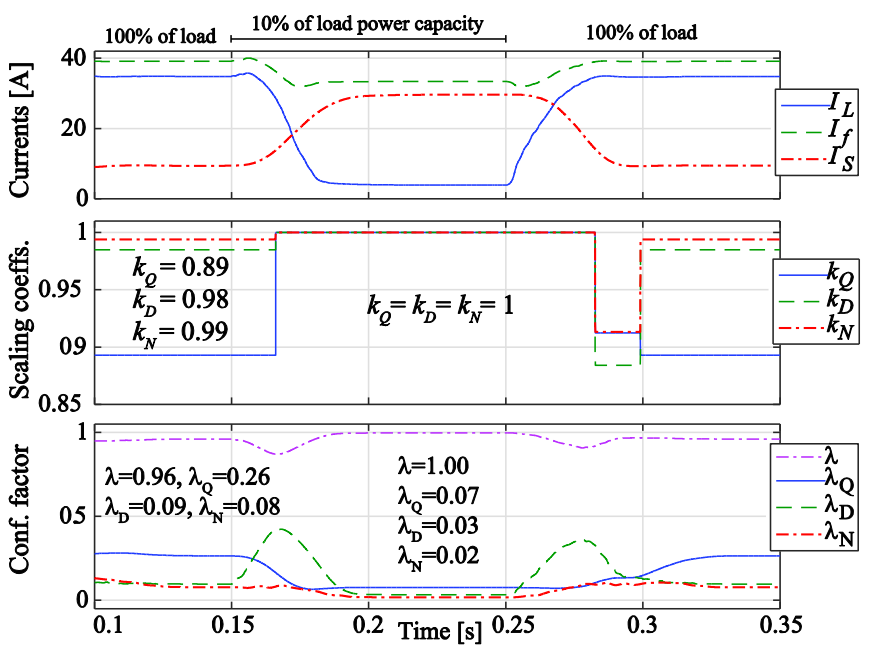

Fig. 6. Optimized compensation under heavy load variation. From top to bottom: currents, scaling coefficients, and PCC conformity factors.

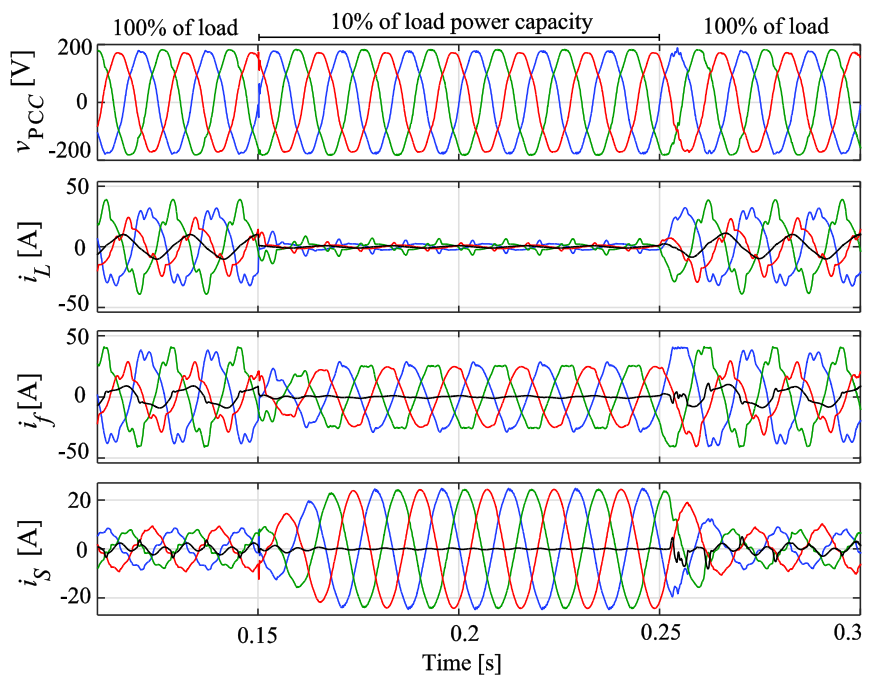

Fig. 7. Optimized compensation under heavy load variation. From top to bottom: PCC voltages, load, filter, and source current waveforms.

in steady state. That being said, the dynamic response of the scaling coefficients is mostly dominated by the rms algorithm used in (5) and (18), which was implemented using moving average filters (MAFs) with one fundamental cycle of time response. The optimization algorithm is updated once per fundamental cycle and the scaling coefficients steady state is achieved in two to three cycles $(\approx 50 \mathrm{~ms})$. The conformity factors have slower dynamic response due to the more complex calculation. However, these factors are used only in PCC analysis and not used into the optimized compensation strategy, which is an online open-loop strategy. That can be verified in Fig. 5, where the filter and source current waveforms show fast response.

2) Heavy Load Variation: In order to evaluate the effectiveness of the proposed compensation strategy under heavy load variation, a $90 \%$ load reduction and increase were set, respectively, at 0.15 and 0.25 s. The results are shown in Figs. 6 and 7, considering the previous distorted voltages. 


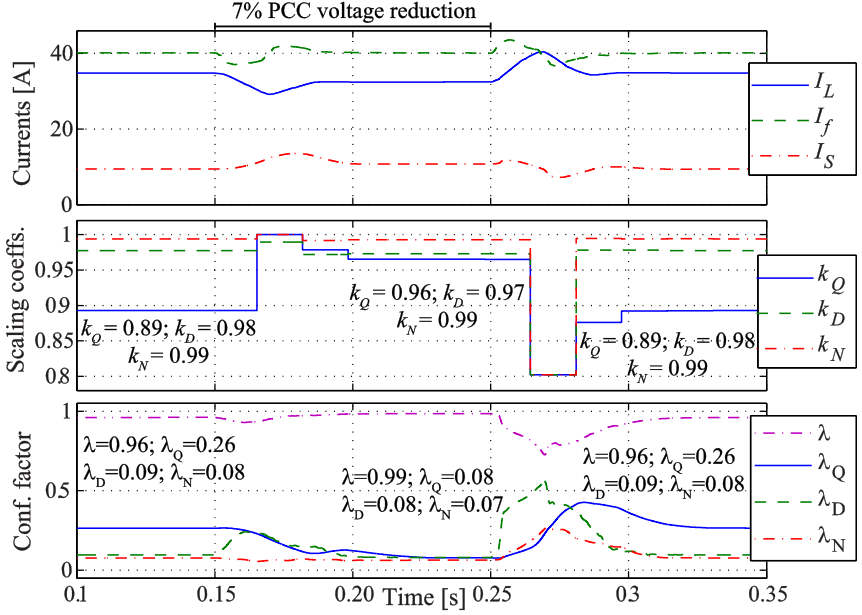

Fig. 8. Optimized compensation under nonideal voltage variation. From top to bottom: currents, scaling coefficients, and PCC conformity factors.
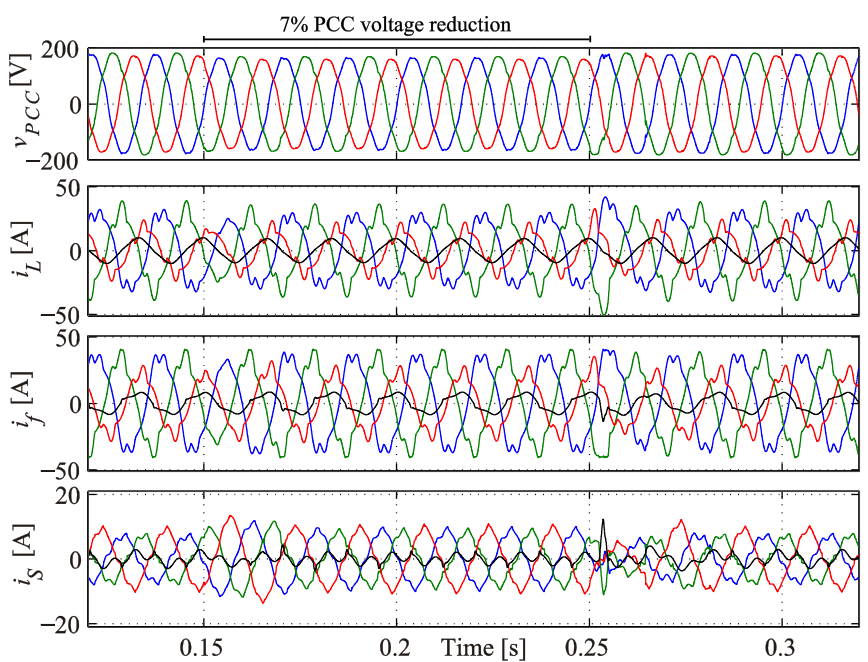

Fig. 9. Optimized compensation under nonideal voltage variation. From top to bottom: PCC voltages, load, filter, and source currents.

The beginning of this simulation matches with the interval \#2 of the previous case study. At $0.15 \mathrm{~s}$, the load is abruptly reduced to $10 \%$ of its nominal power, which increases the available capability $\left(\Delta \boldsymbol{I}_{f}\right)$ for auxiliary services, allowing the EPP to perform full compensation of unwanted current terms $\left(k_{Q}=\right.$ $k_{D}=k_{N}=1$ in Fig. 6). Observe in Fig. 7 that the generated active power is initially drained by the (local) full load, while during the load reduction it is injected to the grid, causing the magnitude of the source currents to increase. Finally, at $0.25 \mathrm{~s}$, the load power returns to its initial value, and the algorithm restores to the same operating point as before the load reduction.

3) Voltage Source Variation: Again, using the previous distorted voltages, source voltages were set to have $7 \%$ voltage reduction at $0.15 \mathrm{~s}$ and restoration to their nominal value at 0.25 s. Figs. 8 and 9 show the results of the system dynamic response during a voltage variation.

At the beginning, EPP operates with partial compensation due to its capability. During the voltage reduction, the load demand

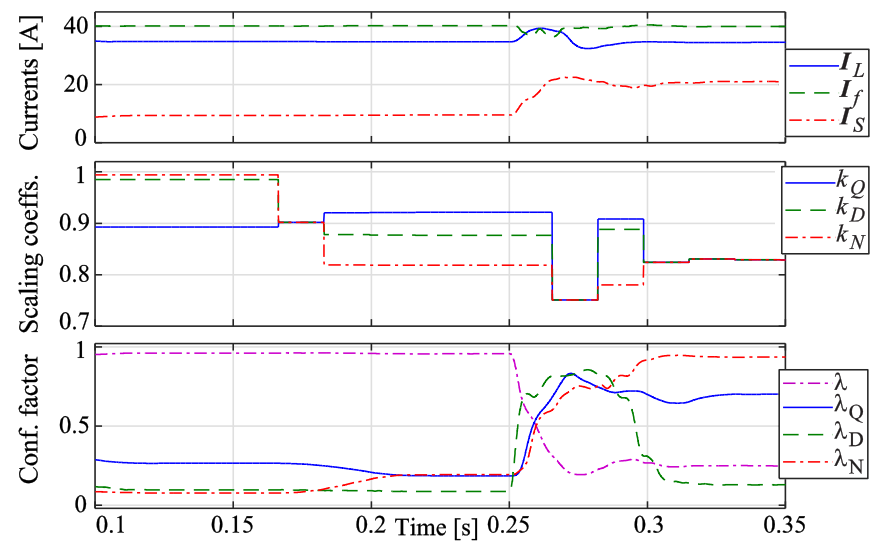

Fig. 10. Optimized compensation under source voltage fault. From top to bottom: currents, scaling coefficients, and PCC conformity factors.

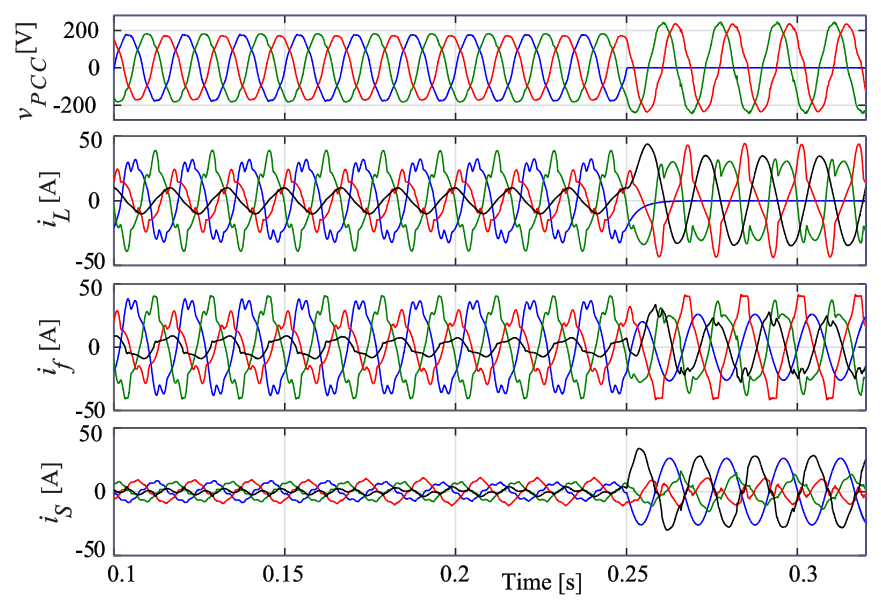

Fig. 11. Optimized compensation under source voltage fault. From top to bottom: PCC voltages, load, filter, and source current waveforms.

decreases and the ac power converter moves to an enhanced compensation point where the optimal solution is $\lambda=0.99$, $\lambda_{Q}=0.08, \lambda_{D}=0.08$, and $\lambda_{N}=0.07$. When the source supply is restored, the scaling coefficients return to their initial optimal point. Observe that EPP capability is fully exploited.

4) Conformity Factor Reference Change and Source Voltage Fault: In order to evaluate the proposed method following commands from distribution provider and during a practical fault occurrence, Figs. 10 and 11 show an online variation of conformity factor reference values and a short-circuit between phase and neutral.

The interval from 0.1 to $0.15 \mathrm{~s}$ corresponds to the interval \#2 of Figs. 4 and 5. At $0.15 \mathrm{~s}$, the conformity factor references were changed to $\left(\lambda^{*}, \lambda_{Q}^{*}, \lambda_{D}^{*}, \lambda_{N}^{*}\right)=(0.92,0.20,0.08,0.15)$, and a fast transient response is observed. After $0.25 \mathrm{~s}$, a short-circuit occurs between the phase $a$ and neutral before PCC, and it is possible to see the current limiter, into the current control loop, restricts the EPP currents during the source voltage fault, while the proposed algorithm keeps running. In steady state during the short-circuit, the EPP performs the nonactive current compensation due to its limited capability. Of course, other 


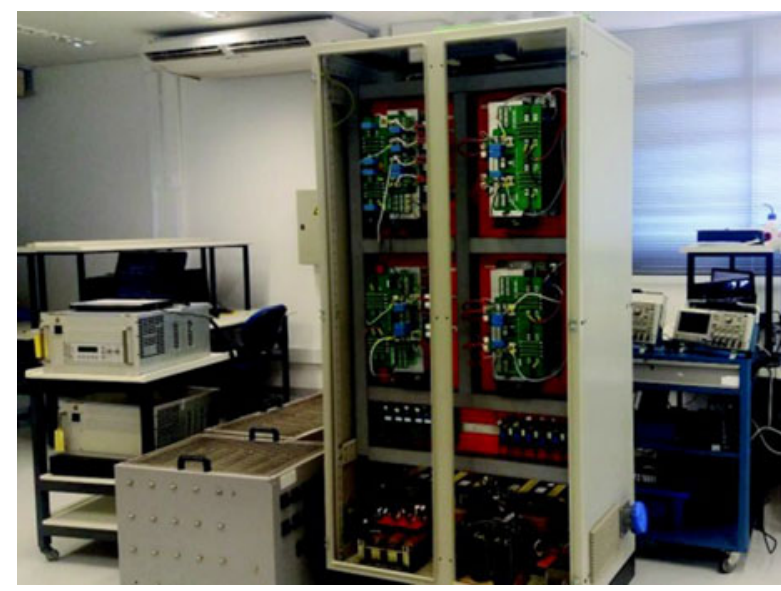

Fig. 12. Experimental laboratory-scale prototype.

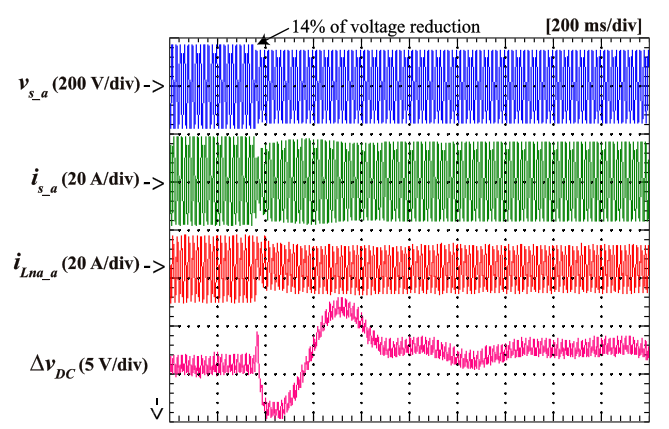

Fig. 13. Voltage variation. From top to bottom: phase a-PCC voltage, source and decomposed nonactive current, and dc-link voltage.

strategy during source fault detection could be applied, such as disconnection of DER or suspension of active power generation.

Other simulation analyses during sinusoidal operation and load dynamics can be found in [24].

\section{EXPERIMENTAL RESULTS}

To experimentally evaluate the proposed compensation scheme, the circuit of Fig. 3 and Table I were developed in laboratory. A general purpose and modular power conditioner prototype was used to configure the EPP, consisting of a three-phase four-leg voltage source inverter with IGBTs (SKM 100GB128D, driven by an SKPC 22/2). The digital control scheme was devised in a fixed-point digital signal processor (TMS320F2812). The three-phase converter is controlled as a shunt APF, driven by the PWM technique with sampling and switching frequency of $12 \mathrm{kHz}$. The duty cycle of the fourth leg is equal to $50 \%$. Details of its parameters and current controller can be found in [28]. A picture of the laboratory-scale prototype is shown in Fig. 12.

At this point, it should be clear that handling the scaling coefficients is equivalent to vary the filter current references, and it has been extensively investigated for both APF and DER [6], [7], [29].

Fig. 13 shows the dc-link voltage response for an APF during a voltage reduction of $14 \%$. In such case, as it is necessary to wait the variation of the dc voltage to start the compensation action,

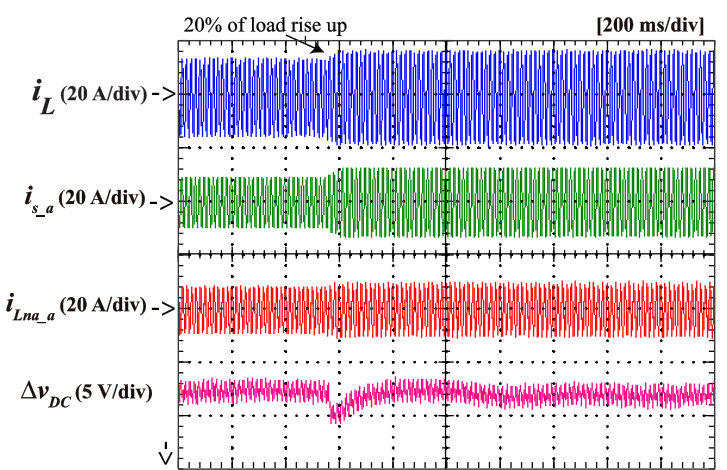

Fig. 14. Load change. From top to bottom: phase a-load current, decomposed nonactive current, source current, and dc-link voltage.

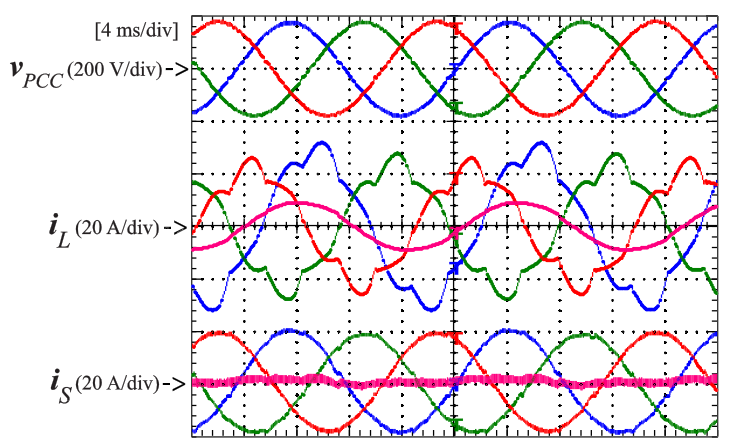

Fig. 15. Experimental results under sinusoidal and symmetrical voltages $\left(k_{Q}=k_{D}=k_{N}=1\right)$. From top to bottom: PCC voltages, load, and source currents.

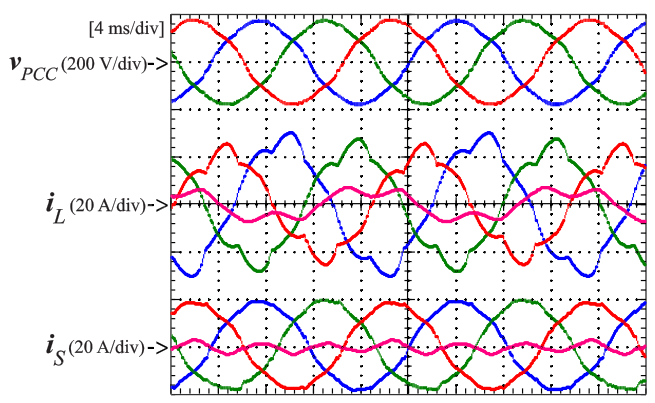

Fig. 16. Experimental results under distorted and symmetrical voltages $\left(k_{Q}=k_{D}=k_{N}=1\right)$. From top to bottom: PCC voltages, load, and source currents.

the dynamic response is typically tens of cycles. Similar behavior can be observed in Fig. 14 during a load power increasing of $20 \%$. As discussed in [28], the dynamics is dominated by the current reference generator, and based on the literature review it is possible to conclude that the system reacts fast enough for steps of scaling coefficients (references) and the compensation can be attained in approximately $50 \mathrm{~ms}$, as discussed in Section IV-B1 due to the updating frequency of the scaling coefficients $\left(k_{y}\right)$.

To evaluate and compare the operation under sinusoidal and distorted voltage conditions, Fig. 15 shows the total nonactive compensation under ideal voltages $\left(\mathrm{THD}_{\mathrm{v}}=0.9 \%\right)$, while Fig. 16 shows under distorted voltages (3\% of third, fifth, and seventh harmonics, totalizing $\mathrm{THD}_{\mathrm{v}}$ of $5.2 \%$ ). Notice that the source currents track the voltage waveforms, characterizing a 
TABLE VI

SOURCE CURRENT HARMONICS UNDER IDEAL AND DISTORTED VOLTAGE CONDITIONS

\begin{tabular}{lcc}
\hline \hline Source current & $\mathrm{THD}_{\text {is }}$ (ideal voltages) & $\mathrm{THD}_{\text {is }}$ (distorted voltages) \\
\hline$i_{\mathrm{sa}}$ & $3.15 \%$ & $5.86 \%$ \\
$i_{\mathrm{sb}}$ & $2.20 \%$ & $5.98 \%$ \\
$i_{\mathrm{sc}}$ & $1.82 \%$ & $5.97 \%$ \\
\hline \hline
\end{tabular}

TABLE VII

Performance of the Power Factor Reference Tracking Under DISTORTED AND SYMMETRICAL VOLTAGES

\begin{tabular}{llllll}
\hline \hline$\lambda^{*}$ & $\mathbf{1 . 0 0 0}$ & $\mathbf{0 . 9 8 0}$ & $\mathbf{0 . 9 5 0}$ & $\mathbf{0 . 9 2 0}$ & $\mathbf{0 . 9 0 0}$ \\
$\lambda$ & $\mathbf{0 . 9 9 7}$ & $\mathbf{0 . 9 8 2}$ & $\mathbf{0 . 9 5 7}$ & $\mathbf{0 . 9 2 8}$ & $\mathbf{0 . 9 1 2}$ \\
$\lambda_{Q}$ & 0.040 & 0.177 & 0.269 & 0.352 & 0.392 \\
$\lambda_{D}$ & 0.017 & 0.052 & 0.066 & 0.079 & 0.083 \\
$\lambda_{N}$ & 0.064 & 0.053 & 0.075 & 0.091 & 0.097
\end{tabular}

resistive load synthesis, see Table VI. The remaining neutral source current is due to the deteriorated voltages. Besides, Table VII shows the system effectiveness to track the power factor reference under distorted and symmetrical voltages.

\section{CONCLUSION}

This paper devised a linear problem to optimize the operation of EPPs, usually applied as APF or DERs with multifunctional capabilities. Using the proposed strategy, EPPs were able to minimize the reactive power, harmonic distortion, and load unbalances, optimizing the results in terms of the most important disturbing phenomena, while injecting available active power in case of DERs fed by intermittent power sources.

The proposed approach took advantage of the formulated linear problem, based on power quality requirements, to define a set of source performance constraints. It goes beyond other approaches that consider only current constraints. In addition, it enabled full exploitation of DERs capability.

The operation dynamics and steady-state behaviors had also been discussed. The former is dominated by the rms algorithm used in (5) and (18), and the latter depends on the implemented control strategy and current controller. However, it is faster than typically dc-link voltage regulators applied to APF or DER applications. The proposed solution had been evaluated through theoretical and experimental results, under ideal and nonideal voltage source operation, demonstrating its effectiveness in a scenario of practical interest. Finally, it is worth mentioning that the proposed methodology was applied here to a three-phase system, though it can be easily adapted to singlephase systems.

\section{APPENDIX}

\section{$\%$ Optimized compensation}

$$
\begin{aligned}
\mathrm{A}= & {\left[\begin{array}{lll}
1 & 1 & 1 ;
\end{array} 100 ;-1\left(1-\lambda_{\mathrm{D}}^{*^{2}}\right) / \lambda_{\mathrm{D}}^{*^{2}}-1 ;-10\left(1-\lambda_{\mathrm{N}}^{*^{2}}\right) /\right.} \\
& \left.\lambda_{N}^{*^{2}} ;-1-1-1 ;-100 ; 0-10 ; 00-1\right] \\
\mathrm{b}= & {\left[\boldsymbol{I}_{\mathrm{a}}^{\mathrm{b}^{2}} \cdot\left(\left(1-\lambda^{2}\right) / \lambda^{2}\right) ; \boldsymbol{I}_{\mathrm{a}}^{\mathrm{b}^{2}} \cdot\left(\lambda_{\mathrm{Q}}^{*^{2}} /\left(1-\lambda_{\mathrm{Q}}^{*^{2}}\right)\right) ;\right.} \\
& \left.\boldsymbol{I}_{a}^{b^{2}} ; \boldsymbol{I}_{\mathrm{a}}^{\mathrm{b}^{2}} ;-\left(\boldsymbol{I}_{\mathrm{na}}-\Delta \boldsymbol{I}_{\mathrm{f}}\right)^{2} ; 0 ; 0 ; 0\right]
\end{aligned}
$$

$\mathrm{x} 0=[0 ; 0 ; 0]$

$\mathrm{x} 0=$ fmincon(@myfun_optimized_comp, $x 0, A, b)$

function $f=$ myfun_optimized_comp(x)

$f=\mathrm{x}(1) \cdot\left(\boldsymbol{I}_{\mathrm{Lr}^{2}}^{\mathrm{b}}\right)+\mathrm{x}(2) \cdot\left(\boldsymbol{I}_{\mathrm{Lv}^{2}}\right)+\mathrm{x}(3) \cdot\left(\boldsymbol{I}_{\mathrm{L}}^{\mathrm{u}^{2}}\right)$

end

\section{$\%$ Minimum compensation}

$x=$ fmincon(@myfun_minimum $\left.{ }_{\mathrm{c}} \mathrm{omp}, x 0, A, b\right)$

function $f=$ myfun_minimum_comp $(\mathrm{x})$

$\mathrm{f}=\mathrm{x}(1) \cdot\left(-1 / \boldsymbol{I}_{\mathrm{Lr}^{2}}^{\mathrm{b}}\right)+\mathrm{x}(2) \cdot\left(-1 / \boldsymbol{I}_{\mathrm{Lv}^{2}}\right)+\mathrm{x}(3) \cdot\left(-1 / \boldsymbol{I}_{\mathrm{L}}^{\mathrm{u}^{2}}\right)$

end

\section{REFERENCES}

[1] E. Romero-Cadaval, B. Francois, M. Malinowski, and Q.-C. Zhong, "Gridconnected photovoltaic plants: An alternative energy source, replacing conventional sources," IEEE Ind. Electron. Mag., vol. 9, no. 1, pp. 18-32, Mar. 2015.

[2] T. Strasser et al., "A review of architectures and concepts for intelligence in future electric energy systems," IEEE Trans. Ind. Electron., vol. 62, no. 4, pp. 2424-2438, Apr. 2015.

[3] $\mathrm{D}$. $\mathrm{Li}$ and $\mathrm{Z}$. Q. Zhu, "A novel integrated power quality controller for microgrid," IEEE Trans. Ind. Electron., vol. 62, no. 5, pp. 2848-2858, May 2015.

[4] F. P. Marafão, D. I. Brandao, A. Costabeber, and H. H. M. Paredes, "Multi-task control strategy for grid-tied inverters based on conservative power theory," IET Renewable Power Gener, vol. 9, no. 2, pp. 154-165, Feb. 2015.

[5] Pacific Gas and Electric Company, "Electric Rule No. 21, generating facility interconnections," Section H.2.i, 2015.

[6] J. Rocabert, A. Luna, F. Blaabjerg, and P. Rodriguez, "Control of power converters in AC microgrids," IEEE Trans. Power Electron., vol. 27, no. 11, pp. 4734-4749, Nov. 2012.

[7] M. I. M. Montero, E. R. Cadaval, and F. B. Gonzalez, "Comparison of control strategies for shunt active power filters in three-phase fourwire systems," IEEE Trans. Power Electron., vol. 22, no. 1, pp. 229-236, Jan. 2007.

[8] S. M.-R. Rafiei, H. A. Toliyat, R. Ghazi, and T. Gopalarathnam, "An optimal and flexible control strategy for active filtering and power factor correction under non-sinusoidal line voltages," IEEE Trans. Power Del., vol. 16, no. 2, pp. 297-305, Apr. 2001.

[9] P. Kanjiya, V. Khadkikar, and H. H. Zeineldin, "Optimal control of shunt active power filter to meet IEEE Std. 519 current harmonic constraints under nonideal supply condition," IEEE Trans. Ind. Electron., vol. 62, no. 2, pp. 724-734, Feb. 2015.

[10] K. R. Uyyuru, M. K. Mishra, and A. Ghosh, "An optimization-based algorithm for shunt active filter under distorted supply voltages," IEEE Trans. Power Electron., vol. 24, no. 5, pp. 1223-1232, May 2009.

[11] J. C. Alfonso-Gil, E. Pérez, C. Ariño, and H. Beltran, "Optimization algorithm for selective compensation in a shunt active power filter," IEEE Trans. Ind. Electron., vol. 62, no. 6, pp. 3351-3361, Jun. 2015.

[12] B. Singh and V. Verma, "Selective compensation of power-quality problems through active power filter by current decomposition," IEEE Trans. Power Del., vol. 23, no. 2, pp. 792-799, Apr. 2008.

[13] T. E. N. Zuniga and J. A. Pomilio, "Shunt active power filter synthesizing resistive load," IEEE Trans. Power Electron., vol. 17, no. 2, pp. 273-278, Mar. 2002.

[14] J. He, Y. W. Li, and F. Blaabjerg, "Flexible microgrid power quality enhancement using adaptive hybrid voltage and current controller," IEEE Trans. Ind. Electron., vol. 61, no. 6, pp. 2784-2794, Jun. 2014.

[15] D. Ahmadi and J. Wang, "Online selective harmonic compensation and power generation with distributed energy resources," IEEE Trans. Power Electron., vol. 29, no. 7, pp. 3738-3747, Jul. 2014.

[16] D. G. Luenberger and Y. Ye, Linear and Nonlinear Programming, 4th ed., F. S. Hillier, Ed. Stanford, CA, USA: Springer-Verlag, 2008.

[17] P. Tenti, H. K. M. Paredes, and P. Mattavelli, "Conservative power theory, a framework to approach control and accountability issues in smart 
microgrids," IEEE Trans. Power Electron., vol. 26, no. 3, pp. 664-673, Mar. 2011.

[18] F. P. Marafão, W. A. Souza, E. V. Liberado, L. C. P. da Silva, and H. K. M. Paredes, "Load analyser using conservative power theory," Przeglad Elektrotechniczny (Elect. Rev.), vol. 89, pp. 1-6, Dec. 2013.

[19] G. W. Chang, "A new approach for optimal shunt active power filter control considering alternative performance indices," IEEE Trans. Power Del., vol. 21, no. 1, pp. 406-413, Jan. 2006.

[20] H. Ginn and G. Chen, "Flexible active compensator control for variable compensation objectives," IEEE Trans. Power Electron., vol. 23, no. 6, pp. 2931-2941, Nov. 2008.

[21] S. Orts-Grau et al., "Selective shunt active power compensator applied in four-wire electrical systems based on IEEE Std. 1459," IEEE Trans. Power Del., vol. 23, no. 4, pp. 2563-2574, Oct. 2008.

[22] C. Cheng, Z. Zeng, H. Yang, and R. Zhao, "Multi-objective optimal compensation of a multi-functional grid-connected inverter for power quality enhancement," in Proc. Int. Conf. Elect. Mach. Syst., Oct. 2012, pp. 1-6.

[23] S. M. R. Rafiei, M. H. Kordi, H. A. Toliyat, and M. Barakati, "IEEE-519 based optimal UPQC design under distorted voltages using Pareto based min-max constrained multi-objective optimization," in Proc. North Amer. Power Symp., Aug. 2011, pp. 1-7.

[24] D. I. Brandao, H. Guillardi Júnior, J. A. Pomilio, and H. K. M. Paredes, "Optimized compensation based on linear programming applied to distributed electronic power processors," in Proc. IEEE Int. Symp. Ind. Electron., Jun. 2015, pp. 373-378.

[25] H. K. M. Paredes, F. P. Marafao, and L. C. P. da Silva, "A comparative analysis of FBD, PQ and CPT current decompositions-Part II: Threephase four-wire systems," in Proc. IEEE Bucharest PowerTech, Jun. 2009, pp. $1-6$.

[26] A. C. Moreira, L. C. P. da Silva, and H. K. M. Paredes, "Applying conservative power theory for analyzing three-phase X-ray machine impact on distribution systems," Elect. Power Syst. Res., vol. 129, pp. 114-125, Dec. 2015.

[27] J. P. Bonaldo, H. K. M. Paredes, A. Costabeber, and J. A. Pomilio, "Adaptive saturation system for grid-tied inverters in low voltage residential micro-grids," in Proc. IEEE Int. Conf. Environ. Elect. Eng., Jun. 2015, pp. $784-789$.

[28] D. I. Brandao, H. K. P. Paredes, A. Costabeber, and F. P. Marafao, "Flexible active compensation based on load conformity factors applied to nonsinusoidal and asymmetrical voltage conditions," IET Power Electron., vol. 2, no. 9, pp. 356-364, Feb. 2016.

[29] S. Buso, T. Caldognetto, and D. Brandao, "Dead-beat current controller for voltage source converters with improved large signal response," IEEE Trans. Ind. Appl., vol. 52, no. 2, pp. 1588-1596, Mar./Apr. 2016.

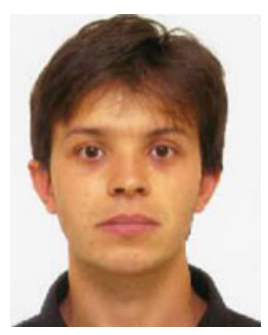

Danilo Iglesias Brandao (S'14-M'16) received the Ph.D. degree in electrical engineering from the University of Campinas, Campinas, Brazil, in 2015.

He was a Visiting Researcher at Colorado School of Mines, USA, in 2009 and 2013, and he was a Visiting Ph.D. Student at University of Padova, Italy, in 2014. He is currently a Professor in the Department of Electrical Engineering, Federal University of Minas Gerais, Belo Horizonte, Brazil. His main research interests include power filters, power quality, distributed compensation strategies, and microgrids.

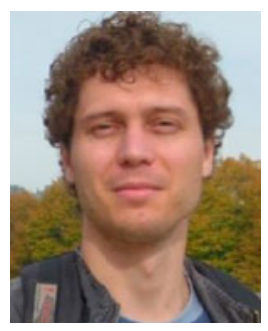

Hildo Guillardi, Jr., was born in Brazil in 1989. He received the B.S. (with Hons.) and M.Sc. degrees in electrical engineering from the Universidade Estadual Paulista (UNESP), Sorocaba, Brazil, in 2011 and 2013, respectively. He is currently working toward the Doctoral degree in electrical engineering at University of Campinas, Campinas, Brazil.

From 2012 to 2014, he was a Lecturer at UNESP. From 2015 to 2016, he was a Visiting Ph.D. Student at University of Padova, Padova, Italy, working on multilevel inverters. His current research interests include power electronics, control of power topologies, multilevel inverters, and power quality.

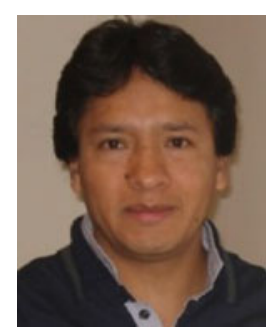

Helmo K. Morales-Paredes (S'10-M'11) received the B.S. degree from the National University of Saint Agustine, Arequipa, Peru, in 2002, and the M.Sc. and Ph.D. degrees from the University of Campinas, Campinas, Brazil, in 2006 and 2011, respectively, all in electrical engineering.

In 2009, he joined the Department of Information Engineering, University of Padova, Padova, Italy, as a Visiting Student. In 2014, he joined the PEMC Group, Department of Electrical and Electronic Engineering, University of Nottingham, Nottingham, U.K., as a Visiting Scholar. Since December 2011, he has been an Assistant Professor with the Universidade Estadual Paulista, Sorocaba, Brazil, where he is a member of the Group of Automation and Integrating Systems. His current research interests include power quality, power theory, and power electronics applied to power systems.

Dr. Morales-Paredes is a Member of the Brazilian Power Electronics Society and Brazilian Automation Society. He received a Prize Paper Award from the IEEE TRANSACTIONS ON POWER ELECTRONICS in 2011.

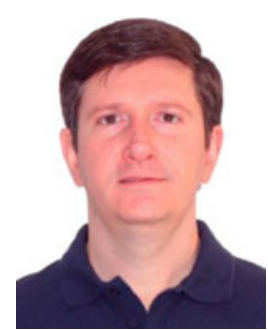

Fernando Pinhabel Marafão (S'95-M'05) received the B.S. degree from the Universidade Estadual Paulista (UNESP), Sorocaba, Brazil, in 1998, and the M.Sc. and Ph.D. degrees from the University of Campinas, Campinas, Brazil, in 2000 and 2004, respectively, all in electrical engineering

In 2002, he joined the Power Electronics Group, University of Padova, Italy, as a Visiting Student working on digital control techniques for active power filters. In 2013, he joined the ACEPS Group, Colorado School of Mines, USA, as a Visiting Scholar on working on autonomous and intelligent distributed energy systems. Since 2005, he has been with UNESP as an Associate Professor in the Group of Automation and Integrating Systems. His current research interests include power definitions under nonsinusoidal and unbalanced conditions, accountability, revenue metering, and digital processing techniques for power electronics and smart grid applications.

Dr. Marafão is a Member of the Brazilian Power Electronics Society and Brazilian Automation Society.

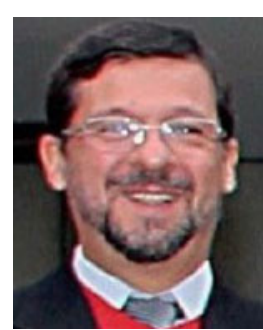

José Antenor Pomilio (M'92-SM'02) was born in Brazil in 1960. He received the B.S., M.S., and $\mathrm{Ph} . \mathrm{D}$. degrees in electrical engineering from the University of Campinas, Campinas, Brazil, in 1983, 1986, and 1991, respectively.

From 1988 to 1991, he was the Head of the Power Electronics Group, Brazilian Synchrotron Light Laboratory. He was a Visiting Professor at University of Padova in 1993 and 2015 and at Third University of Rome in 2003, both in Italy. $\mathrm{He}$ is a Professor with the School of Electrical and Computer Engineering, University of Campinas, where he has been teaching since 1984. His main research interests include power electronics and power quality.

Dr. Pomilio was the President of the Brazilian Power Electronics Society during 2000-2002 and a Member of the Administrative Committee of the IEEE Power Electronics Society during 1997-2002. He is currently an Associate Editor of the IEEE TRANSACTIONS ON POWER ELECTRONICS. 